\title{
Sustainable Agricultural Development in the Coal Mining Region: Specific Characteristics and Conditions (a Case Study in the Kemerovo Region)
}

\author{
Elmira Lubkova ${ }^{1 *}$, Anna Shilova $^{1}$, Maria Kumaneeva $^{1}$, and Vladimir Mischenko ${ }^{1}$ \\ ${ }^{1}$ T. F. Gorbachev Kuzbass State Technical University, Kemerovo, Russia
}

\begin{abstract}
Agricultural development is an essential condition for the balanced socio-economic development of any region. The level of development in the agricultural sector impacts food security of the population in the given region, while the quality of agricultural output and the price level affects the standard and the quality of living of the population. The link between the level of agricultural development and socio-economic development of rural areas is important. On the one hand, well-developed agriculture preserves rural areas, contributes to job creation in rural areas and helps develop social rural infrastructure. On the other hand, human capacity of agriculture depends on the socio-economic development of rural areas. There are significant variations in agriculture among different regions. Industrial regions often have unfavourable conditions and factors for agricultural development, which is especially evident in mining areas with a specific demographic situation, unfavourable environmental conditions, low interest of business in the development of agriculture. This article uses a case study of the Kemerovo region-Kuzbass to analyze the peculiarities of agricultural development in the coal mining area. The article gives the basic indicators characterizing agricultural development, assesses the adverse limiting factors for agricultural development, assesses the implementation of agricultural functions in the industrial region and highlights the main prospects for agricultural development in the Kemerovo region-Kuzbass.
\end{abstract}

\section{Introduction}

In the Russian Federation, there exist large disparities in the socio-economic development of the regions. Geographic disparities of the regions historically predetermined the characteristics of different regions: climatic, demographic and cultural disparities are substantial. Labour force is distributed unevenly over the territory of the Russian Federation.

\footnotetext{
*Corresponding author: author@email.org
} 
There is a great deal of dependence of specific industries on the climatic conditions and socio-economic development of the region. Such industries primarily include the agroindustrial complex, in particular agriculture as its key link.

Earlier studies with the participation of the authors have shown that the situation is most favourable in the regions with the developed mining sector. In such regions, mining companies may be located throughout the region and mineral extraction has a significant and crucial role; therefore the potential for agricultural development is considerably limited in terms of geographic areas. The development of the mining industry provokes environmental degradation, which adversely affects the potential of agriculture and the quality of agricultural products. Difficulties in the agricultural development and high, often non-competitive prices of agricultural producers create a problem of high dependence on imports and inter-regional imports of food. Significant disparities in the basic food consumption pattern are emerging. These patterns explain the relevance of the study on the regional agricultural development in mining regions.

This article studies the specific characteristics of the agricultural development in the Kemerovo region-Kuzbass, which is a typical coal mining region.

Works of modern researchers devoted to the development of the agro-industrial complex, in particular agriculture in mining regions, constitute the theoretical base of the study.

Statistical information of the Unified Interdepartmental Statistical Information System, data from the territorial bodies of the Federal State Statistics Service by constituent entities of the Siberian Federal District are used as the input data for the study.

\section{Results and Discussion}

\section{Information Review}

Modern researchers pay considerable attention to the issues of sustainable agricultural development. Sustainable agriculture contributes to the sustainable socio-economic development of the region, enhancing food supply of the region and the competitiveness of agricultural products, and as a consequence, food security of the state [1, 2, 3].

Since agriculture is highly dependent on many objective climatic and geographic, socioeconomic and environmental factors, considerable attention is focused on the problems of regional management of sustainable agriculture [4,5].

Mining regions face the greatest difficulties in the creation of conditions for the agricultural development [6]. One of the most important challenges is prevalence of mining companies, withdrawal of agricultural lands from the economic turnover, decrease in the share of the rural population. The development of urbanization adversely affects the possibility of successful operation of agricultural enterprises in the region. The reduction of territories and the emergence of staffing problems entail adverse environmental effects [7]. The role of green agriculture is becoming common [8-10], but it is especially noticeable in mining regions, where the adverse effects of mining are most clearly seen [11].

To assess the prospects of sustainable agricultural development, it is useful to study the specifics of the implementation of agricultural functions [12], while it should also be understood that agricultural functions are transformed in mining regions [13], and sustainable agriculture requires the implementation of innovative modalities [14] and advanced business models [15]. 


\section{The current agricultural development in the Kemerovo region-Kuzbass}

The Kemerovo region-Kuzbass is a typical region with a well-developed mining sector, nearly a third of the regional product is created by mining companies. The highest level of urbanization behind the Urals (more than 70\%), the unfavourable environmental situation and the lowering capacity of agriculture both due to the reduction of agricultural land and the low comparative performance of agricultural enterprises as opposed to mining companies makes the study of opportunities for the agricultural development and the implementation of its main functions quite relevant.

By and large, over the five-year period there has been an increase in production volumes in prices applicable at the time. However, an increase of only $8.64 \%$ over the fiveyear period with account of the rate of inflation is not sufficient to infer there is an increase in real production. There is an uneven situation in livestock farming and crop production: crop production increased by almost $30 \%$ from 2016 to 2020, while livestock production decreased by $8.89 \%$ (Table 1 ), due to the low poor profitability of livestock production and higher risks.

Table 1. Key indicators of agricultural development in the Kemerovo region-Kuzbass, mln rubles (in prices applicable at the time)

\begin{tabular}{|l|c|c|c|c|c|c|}
\hline & $\mathbf{2 0 1 6}$ & $\mathbf{2 0 1 7}$ & $\mathbf{2 0 1 8}$ & $\mathbf{2 0 1 9}$ & $\mathbf{2 0 2 0}$ & $\begin{array}{c}\text { Growth } \\
\text { rate }\end{array}$ \\
\hline $\begin{array}{l}\text { Agricultural } \\
\text { production }\end{array}$ & $48,596.1$ & $48,027.9$ & $46,912.2$ & $47,806.4$ & $52,797.1$ & 108.64 \\
\hline including: & & & & & & \\
\hline $\begin{array}{l}\text { crop } \\
\text { production }\end{array}$ & $22,308.6$ & $21,757.8$ & $21,290.3$ & $22,308.7$ & $28,847.2$ & 129.31 \\
\hline livestock & $26,287.5$ & $26,270.1$ & $25,621.9$ & $25,497.7$ & $23,949.9$ & 91.11 \\
\hline
\end{tabular}

The analysis of the main types of agricultural products shows a decrease in the real output of all types of products, except for grain and eggs. The most unfavourable situation is found in the production of cattle and poultry $(-7.39 \%)$, milk $(-9.26 \%)$ and vegetables ($9.65 \%$ ) (Table 2). It is important to point out that milk and vegetables are the products the consumption of which in the Kemerovo region-Kuzbass is traditionally deep below the standard values.

Table 2. Production of main types of agricultural products in the Kemerovo region-Kuzbass, thousand tonnes

\begin{tabular}{|l|c|c|c|c|c|c|}
\hline & $\mathbf{2 0 1 6}$ & $\mathbf{2 0 1 7}$ & $\mathbf{2 0 1 8}$ & $\mathbf{2 0 1 9}$ & $\mathbf{2 0 2 0}^{\mathbf{1})}$ & $\begin{array}{c}\text { Growth } \\
\text { rate }\end{array}$ \\
\hline $\begin{array}{l}\text { Grain (in weight } \\
\text { after processing) }\end{array}$ & 928.3 & $1,077.1$ & 996.4 & $1,107.8$ & $1,288.8$ & 138.83 \\
\hline Potato & 456.8 & 460.7 & 474.8 & 425.5 & 455.1 & 99.63 \\
\hline Vegetables & 143.0 & 129.3 & 123.9 & 126.8 & 129.2 & 90.35 \\
\hline $\begin{array}{l}\text { Slaughter cattle } \\
\text { and poultry }\end{array}$ & 127.1 & 128.1 & 129.4 & 131.7 & 105.0 & 82.61 \\
\hline Milk & 333.8 & 326.7 & 302.6 & 302.7 & 302.9 & 90.74 \\
\hline Eggs, mln pcs & 1129.6 & 1193.0 & 1168.0 & 1089.3 & 1193.5 & 105.66 \\
\hline
\end{tabular}

Therefore, with regard to the volume of agricultural production in the Kemerovo region-Kuzbass, it should be borne in mind that a significant decrease in their volume seriously jeopardizes the stable socio-economic development of the region, which requires a comprehensive study of the specific characteristics of agricultural development, 
identification of the most vulnerable sectors and development of measures to support them.

\section{Assessment of the implementation of agricultural functions in the Kemerovo region-Kuzbass}

Currently, the implementation of agricultural functions depends on the specific characteristics of the region. For instance, the transformation of agricultural functions in industrial regions is the result of the current state of the sectors and subcomplexes of the regional agro-industrial complex.

The main functions of agriculture include economic, social, production, environmental, tourism and recreational functions [13]. The indicators of implementation of the main functions are shown in Table 3.

Table 3. Indicators of implementation of the main agricultural functions

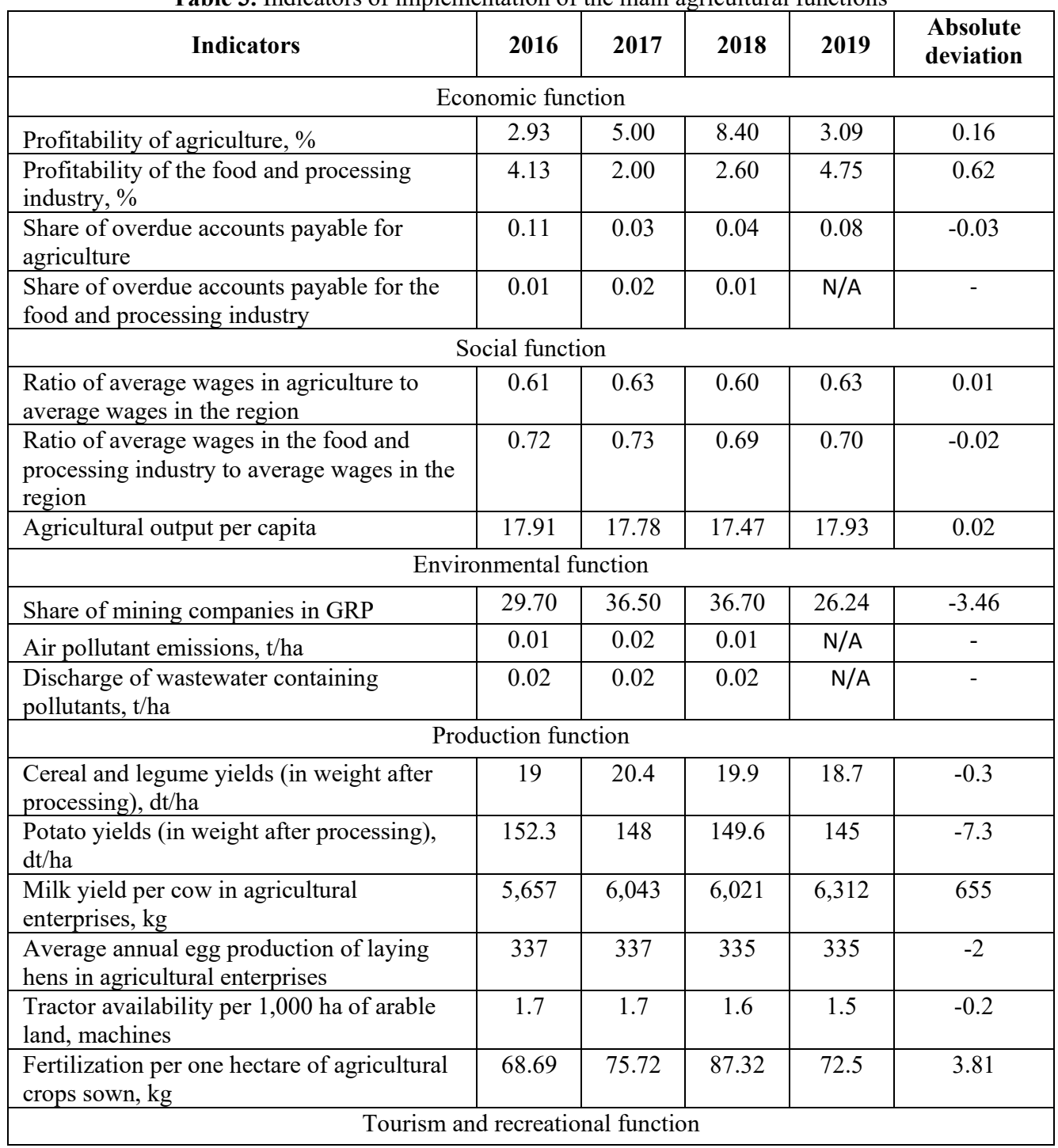




\begin{tabular}{|l|c|c|c|c|c|}
\hline $\begin{array}{l}\text { Number of visits to museums of the } \\
\text { Ministry of Culture of the Russian } \\
\text { Federation }\end{array}$ & $1,313.6$ & $1,309.2$ & $1,119.8$ & $1,321.5$ & 7.9 \\
\hline Number of health resort facilities & 43 & 44 & 43 & 43 & 0 \\
\hline
\end{tabular}

As shown in Table 3, the indicators characterizing implementation of the economic function of agriculture are not quite favourable, but have positive trends. Low profitability is a negative trend.

Low wages in the agricultural sector and food and processing industry reduces human capacity of the agro-industrial complex in the region and adversely affects the level of implementation of the social function.

A high proportion of mining operations and significant emissions into the atmosphere and discharge of wastewater containing pollutants can have a negative impact on the quality of agricultural products and food produced in the region and raise the question of greening agriculture in the Kemerovo region.

There is a decrease in the effectiveness of crop production and annual egg production, reduced tractor availability per 1000 hectares of arable land, which negatively characterizes implementation of the production function of agriculture.

There is clearly a need to quantify implementation of agricultural functions in comparison with other regions, since the regional agricultural development in a market economy depends on its comparative advantages as opposed to other regions, so it is useful to use not separate values that characterize the level of implementation of agricultural functions, but rather indices reflecting the level of these indicators in correlation in relation to the regions under comparison. The indices for direct indicators are calculated as the ratio of the regional indicator to the reference value among the regions under comparison, and for inverse indicators - as the ratio of the reference value to the value achieved in the region. Thus, the leader has an index equal to 1 .

In this study, the regions of the Siberian Federal District, with which the Kemerovo region has the most active commodity exchange of agricultural products, were chosen as the regions of comparison.

Statistical information of the Unified Interdepartmental Statistical Information System, and data from the territorial bodies of the Federal State Statistics Service by constituent entities of the Siberian Federal District (SFD) are used as the input data for the study.

Table 4. Comparison of the level of implementation of agricultural functions in the Kemerovo region-Kuzbass and in other SFD constituent entities

\begin{tabular}{|l|c|c|c|c|c|c|}
\hline \multicolumn{1}{|c|}{ Indicators } & $\mathbf{2 0 1 6}$ & $\mathbf{2 0 1 7}$ & $\mathbf{2 0 1 8}$ & $\mathbf{2 0 1 9}$ & $\begin{array}{c}\text { Absolute } \\
\text { deviation }\end{array}$ \\
\hline \multicolumn{3}{|c|}{ Economic function } \\
\hline Profitability of agriculture & 0.16 & 0.36 & 0.67 & 0.19 & 0.02 \\
\hline $\begin{array}{l}\text { Profitability of the food and processing } \\
\text { industry }\end{array}$ & 0.32 & 0.17 & 0.17 & 0.43 & 0.12 \\
\hline $\begin{array}{l}\text { Share of overdue accounts payable for } \\
\text { agriculture }\end{array}$ & 0.02 & 0.09 & 0.02 & 0.02 & 0.00 \\
\hline $\begin{array}{l}\text { Share of overdue accounts payable for the } \\
\text { food and processing industry }\end{array}$ & 0.05 & 0.56 & 0.04 & - & & - \\
\hline \multicolumn{2}{|c|}{ Social function } & & & & \\
\hline $\begin{array}{l}\text { Ratio of average wages in agriculture to } \\
\text { average wages in the region }\end{array}$ & 0.65 & 0.64 & 0.62 & 0.68 & 0.02 \\
\hline $\begin{array}{l}\text { Ratio of average wages in the food and } \\
\text { processing industry to average wages in the } \\
\text { region }\end{array}$ & 0.64 & 0.84 & 0.82 & 0.84 & 0.20 \\
\hline
\end{tabular}




\begin{tabular}{|l|c|c|c|c|c|}
\hline Agricultural output per capita & 0.30 & 0.33 & 0.31 & 0.29 & -0.01 \\
\hline \multicolumn{7}{|c|}{ Environmental function } \\
\hline Share of mining companies in GRP & 0.01 & 0.01 & 0.01 & - & - \\
\hline Air pollutant emissions & 0.01 & 0.01 & 0.00 & - & - \\
\hline $\begin{array}{l}\text { Discharge of wastewater containing } \\
\text { pollutants }\end{array}$ & 0.00 & 0.00 & 0.00 & - & - \\
\hline \multicolumn{7}{|c|}{ Production function } \\
\hline $\begin{array}{l}\text { Cereal and legume yields (in weight after } \\
\text { processing) }\end{array}$ & 0.69 & 0.89 & 0.87 & 0.84 & 0.15 \\
\hline Potato yields (in weight after processing) & 0.89 & 0.89 & 0.92 & 0.85 & -0.04 \\
\hline Milk yield per cow in agricultural enterprises & 0.90 & 0.91 & 0.82 & 0.86 & -0.04 \\
\hline $\begin{array}{l}\text { Average annual egg production of laying } \\
\text { hens in agricultural enterprises }\end{array}$ & 0.92 & 0.97 & 0.96 & 0.96 & 0.04 \\
\hline $\begin{array}{l}\text { Tractor availability per 1000 ha of arable } \\
\text { land }\end{array}$ & 0.36 & 0.30 & 0.29 & 0.27 & -0.09 \\
\hline $\begin{array}{l}\text { Fertilization per one hectare of agricultural } \\
\text { crops sown }\end{array}$ & 0.19 & 0.17 & 0.18 & 0.22 & 0.04 \\
\hline \multicolumn{7}{|c|}{ Tourism and recreational function } \\
\hline $\begin{array}{l}\text { Number of visits to museums of the Ministry } \\
\text { of Culture of the Russian Federation }\end{array}$ & 0.75 & 0.74 & 0.65 & 0.71 & -0.04 \\
\hline Number of health resort facilities & 1.00 & 1.00 & 1.00 & 1.00 & 0.00 \\
\hline
\end{tabular}

The reference level of implementation of the economic and social functions of agriculture in the Kemerovo region-Kuzbass throughout 2016-2019 remained below average, while there was a declining trend in the indicator. The worst values are recorded for the reference level of implementation of the environmental function due to the evident mining specialization of the region. The production function of agriculture in the Kemerovo region-Kuzbass is implemented at an average level. Despite objective difficulties in the development of agriculture in the industrial region, this indicator has positive dynamics due to productive and investment capacities. The tourism and recreational function of agriculture is implemented at a high level.

Thus, the overall reference level of implementation of agricultural functions in the Kemerovo region-Kuzbass during the period is assessed as average or below average.

\section{Conclusion}

The study found that for the Kemerovo region-Kuzbass the production and tourism and recreational functions of agriculture are characterized by a higher level of implementation. Further development of agriculture in the region should take into account the need to promote the economic function of agriculture. At the same time, the low indicators of implementation of the economic and environmental functions of agriculture create risk factors for the sustainable development of agriculture in the region. The sustainable development of agriculture in the Kemerovo region-Kuzbass requires that measures be taken at the regional level to support the economic efficiency of agricultural production. 


\section{References}

1. P. Koohafkan, M. A. Altieri, E. H.Gimenez, International Journal of Agricultural Sustainability (2011)

2. A. Kotarev. IOP Conference Series: Earth and Environmental Science 274(1), 012035 (2019)

3. A. Jambor, S. Babu, Competitiveness of Global Agriculture Policy Lessons for Food Security, 197 (2016)

4. I. C. De Jesus, M. S. Islam, The Challenge of Food Security. Regional initiatives on food security, 255 (2012)

5. K. Sturman, O. Bello, Opportunities and Challenges for Local Food Procurement by Mining Companies in Tanzania and Mozambique, 35 (2014)

6. S. A. Shelkovnikov, E. M. Lubkova, A. E. Shilova, Economics, labor, management in agriculture, 7(52), 51 (2019)

7. D. Satterthwaite, G. McGranahan, C. Tacoli. Philos Trans R Soc Lond B Biol Sci. Urbanization and its implications for food and farming, 9, 2809 (2010)

8. N. Jankelova, D. Masar, S. Moricova. Agricultural Economics (Czech Republic), 63(6), 247 (2017)

9. P.C. Struik, T. W. Kuyper, Agronomy for Sustainable Development, 37 (2017)

10. I. N. Merenkova, Ostrovsky Readings, 1, 224 (2017)

11. S. Bereznev, E. Lubkova., A. Shilova, G. Ermolaeva, IOP conference series: materials science and engineering. International science and technology conference "FarEastCon-2019", 082012 (2020)

12. O. Kosenchuk, O. Shumakova, A. Zinich, S. Shelkovnikov, A. Poltarykhin. Journal of Environmental Management and Tourism, 5(37), 991 (2019)

13. S.A. Shelkovnikov, E.M. Lubkova, A.E. Shilova. Russian agricultural economy, 1, 17 (2021)

14. J. Potts, T. Kastelle. Economic Analysis and Policy. 54, 96 (2017).

15. M.N. Dudin, N.V Lyasnikov,. L.S. Leont'eva, K.J. Reshetov, V.N. Sidorenko, Biosciences Biotechnology Research Asia, 12(1), 887 (2015) 